\title{
Beijing - Tianjin - Hebei Traffic Integration, Spatial Spillover and Economic Growth—Based on Space Panel Model
}

\author{
Xue Zhang ${ }^{\text {a }}$, Meiqing Zhang ${ }^{\mathrm{b}}$
}

School of Economics and Management, Beijing Jiaotong University, Beijing 100044, China

axuezhang6@163.com,,14120534@bjtu.edu.com

Keywords: Traffic Integration, Spatial Spillovers, Economic Growth.

\begin{abstract}
Based on the panel data of cities in Beijing-Tianjin-Hebei region from 2003 to 2014, this paper analyzes the relationship between transportation infrastructure, spatial spillover and economic growth through spatial error and spatial lag model and different weight matrixes. The study finds that the economic development of Beijing-Tianjin-Hebei has a significant positive spatial correlation and shows a trend of strengthening year by year. Traffic integration has a positive role in promoting economic development, and the influence of the road is greater than that of the railway. But the railway has shown increasing returns to scale, the road is diminishing returns. Regional economic link strength is greater than that of distance, and the spatial spillover effect of the traffic infrastructure based on the scale matrix is largest. The spillover effect of the secondary industry is higher than that of the third industry.
\end{abstract}

\section{Introduction}

At present, the integration of Beijing-Tianjin-Hebei is a major national development strategy, while the traffic integration is the pioneer of the coordinated development of Beijing-Tianjin -Hebei, which plays a leading role in optimizing the economic growth and regional spatial distribution of Beijing-Tianjin-Hebei urban agglomeration. When cities plan the construction of transportation infrastructure, they always focus on their own administrative region of economic growth, the spillover effect is not considered. But investment in transport infrastructure must break the boundaries of administrative power.

Therefore, this paper will focus on the following issues: (1) Does spatial spillover effect exist? (2) If there is a spatial spillover effect, is it positive or negative? Are there any differences in different transport infrastructures? (3) Considering different weight matrix, the paper compares the spillover effect on the regional economic growth.

\section{Literature References}

Based on the traditional production function, the scholars have mainly studied the existence of spillover effects and its value[1]. Zhang Xueliang based on provincial panel data in China from 1993 to 2009,through the method of spatial econometrics, the empirical analysis shows that the spatial spillover effect of China's transportation infrastructure on regional economic growth is very significant[2]. From the provincial level research, scholars mainly use the simple geographically adjacent second-order matrix to study the spillover effect in regional disparities and different modes of transportation. The scale of investment in transport infrastructure and the gap between economic growth in the eastern, central and western regions are very large, and the spatial distribution is very uneven, forming a gradual gradient from east to west, and the transportation infrastructure has obvious positive space spillover effect for regional economic growth[3,4]. Most of the research results show that the spatial spillover effect of railway is obviously larger than that of highway, and the local economic growth effect of highway infrastructure is significant[5]. In the micro-field, many scholars have studied the spillover effects of transport infrastructure on transport infrastructure for private and public capital investment, manufacturing productivity, enterprise inventory and inventory costs, foreign trade growth, market access and location advantages[6].

But the existing literature has the following shortcomings. The spillover effect of transport 
infrastructure is not a simple linear relationship, linear model setting will produce biased estimates. The transport infrastructure is a functional network, and its spillover effect is also subject to the law of diminishing marginal returns. The spatial adjacency weight matrix is too simple. So this paper will consider different weight matrix.

\section{Methodology}

Transportation infrastructure will promote economic growth in two aspects, one is to directly stimulate economic growth through the multiplier effect, and the other through the impact of other input factors to change the production efficiency of output. Therefore, transport infrastructure is a significant factor affecting total factor productivity. Based on the traditional production function, we set ordinary panel model as:

$\ln Y=\alpha+\beta 1 \ln K+\beta_{2} \ln L+\beta_{3} \ln R A I L+\beta_{4}(\operatorname{lnRAIL})^{2}+\beta_{5} \operatorname{lnROAD}+\beta_{6}(\operatorname{lnROAD})^{2}+\varepsilon$

Where $\alpha$ is a constant term, RAIL is a railway, ROAD is a highway, and $\varepsilon$ is an error term.

Considering the spatial factors, we will use the spatial lag or spatial error model, the expression of the two models are as follows:

$$
\begin{aligned}
& \ln Y_{i t}=\beta X_{i t}+\rho \sum_{j=1}^{N} W_{i j} y_{j t}+u_{i}+\varepsilon_{i t} \\
& \ln Y_{i t}=\beta X_{i t}+u_{i}+\varphi_{i t}, \quad \varphi_{i t}=\lambda \sum_{j=1}^{N} W_{i j} \varphi_{i t}+\varepsilon_{i t}
\end{aligned}
$$

Where $\mathrm{i}$ is the cities, $\mathrm{t}$ is the year, $\mathrm{X}_{\mathrm{it}}$ is the set of explanatory variables in the normal panel model, $W_{i j}$ is the element of the spatial weight matrix, and $u_{i}$ is the individual effect.

Geographic distance matrix is based on the geographical center of the two regions between the number of kilometers to establish. The market size matrix and the industrial structure matrix are constructed according to the following formula:

$$
\mathrm{W}_{\mathrm{ij}}=\frac{1 /\left|\mathrm{x}_{\mathrm{i}}-\mathrm{x}_{\mathrm{j}}\right|}{\sum_{\mathrm{j}} 1 /\left|\mathrm{x}_{\mathrm{i}}-\mathrm{x}_{\mathrm{j}}\right|}
$$

The above related raw data are from China Transportation Yearbook, China Statistical Yearbook and China City Statistical Yearbook. A few cities lack some data, and they can be complemented by referring to the statistical bulletin of national economy and social development in these cities . For the missing data, use the interpolation method to supplement.

\section{Results}

In order to explore the spatial correlation of economic development in Beijing-Tianjin- Hebei, the global Moran'I index of Beijing, Tianjin and Hebei in 2003 and 2014 was first plotted by using GEODA software (Fig.1 and Fig.2). The Moran'I index in Figure 1 and Figure 2 is positive, indicating that there is positive spatial correlation in the economic development of Beijing-TianjinHebei area. In figure 1 , the index value is 0.0034 , but in figure 2 , the value is 0.1882 , indicating that in the development of more than 10 years, regional economic development on the spatial contact is gradually closer.

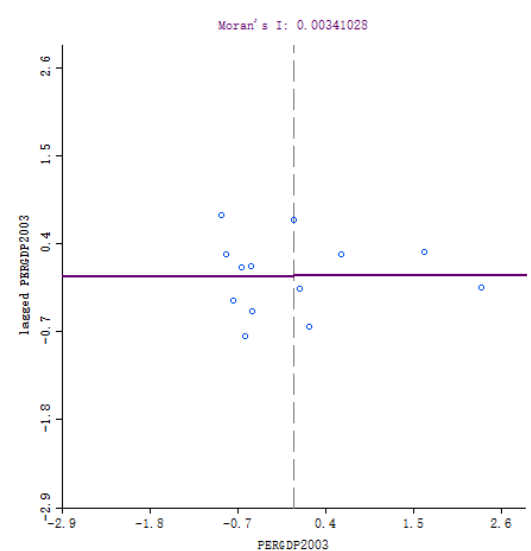

Fig.1 Per capita GDP Moran'I index in 2003

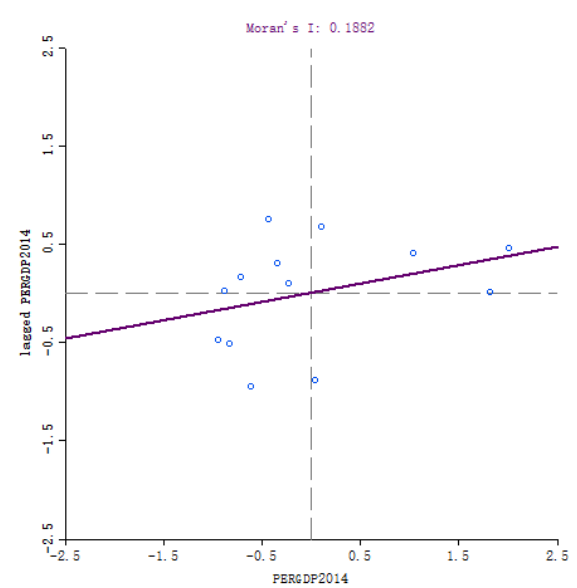

Fig. 2 Per capita GDP Moran'I index in 2014 in 2003 and 2014 is described by the quartile 
diagram, see Fig. As can be seen from the figure, both the road or the spatial distribution of railways, are very unbalanced. By 2014 the most densely populated areas of railways and highways are Beijing, Baoding and Tianjin.
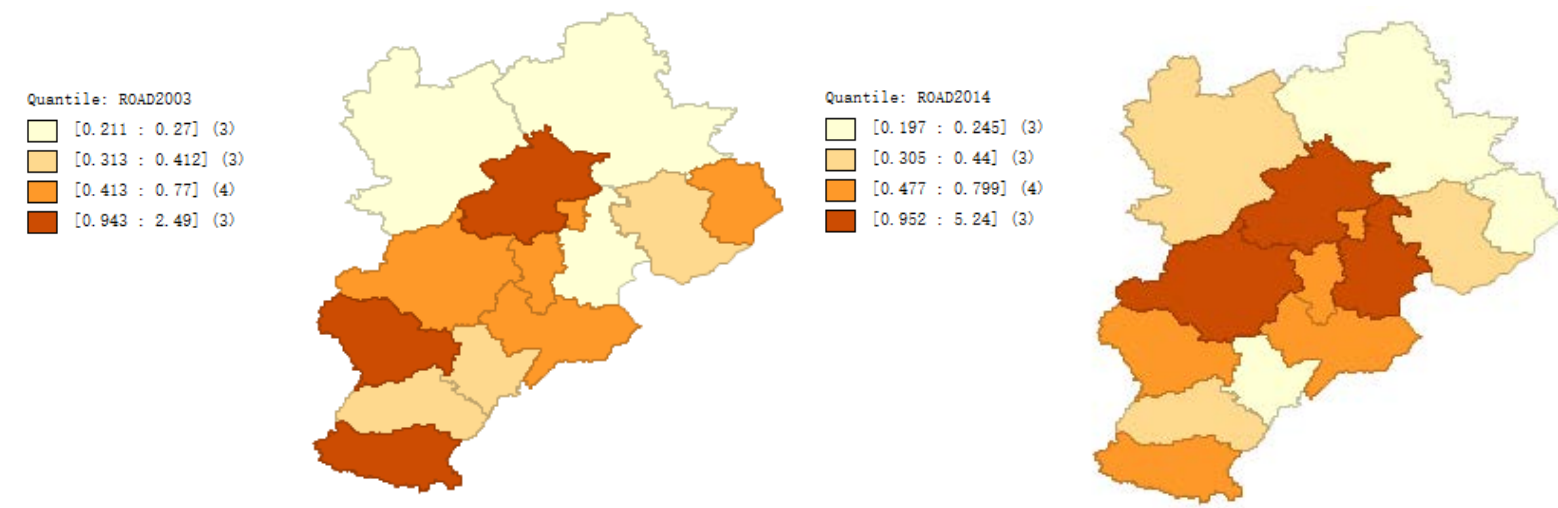

Fig. 3 Spatial distribution of highways in 2003

Fig.4 Spatial distribution of highways in 2014

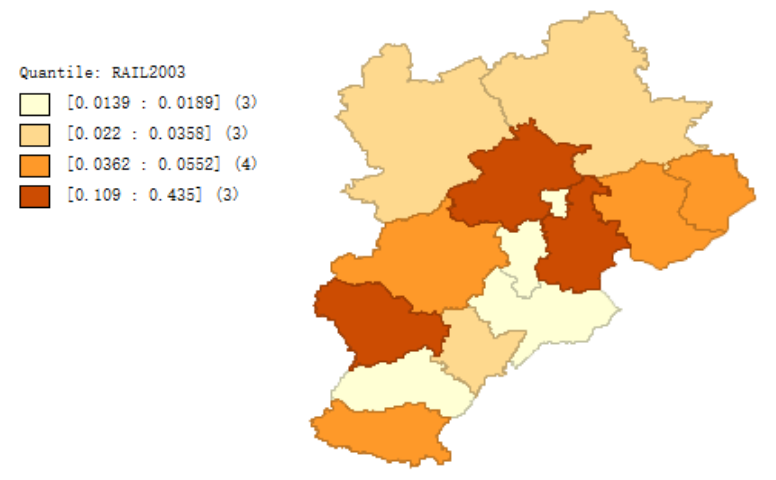

Fig.5 Spatial distribution of railways in 2003
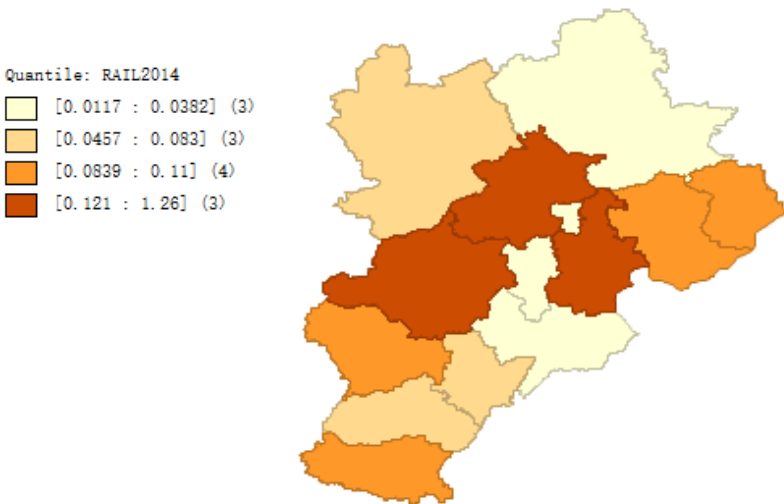

Fig.6 Spatial distribution of railways in 2014

Based on the results of spatial lag and spatial error model, it is concluded that railways and highways have a great effect on economic development, and the influence of highway is bigger than railway. Based on the quadratic analysis of transportation infrastructure, the railway shows the increasing returns to scale, while the highway is characterized by diminishing returns to scale. At the same time, there is a positive spatiotemporal effect on spatial contiguity between regions. The spatial spillover effect of transportation infrastructure based on scale matrix is the largest, the spillover effect of the second industry is higher than that of the third industry.

\section{Summary}

According to the results of this paper, the following suggestions are put forward to better promote the coordinated development of Beijing- Tianjin-Hebei: First, we should make full use of the positive spillover effect between cities, strengthen economic cooperation and interaction, realize complementary advantages, and further narrow the difference of economic development. Second, strengthen the construction of high-grade highway infrastructure, increase the proportion of high-grade highway mileage, so as to give full play to the role of highway infrastructure. Third, reduce the highway tolls in order to reduce transaction costs and strengthen the role of market in the allocation of resources. Fourth, for the secondary industry dominant areas, we should further strengthen the railway and highway transportation infrastructure construction, for the third industry dominated areas we should strengthen the network and other virtual infrastructure construction.

\section{References}

[1] Zhang Xueliang. Has transport infrastructure promoted regional economic growth? With an analysis of the spatial spillover effects of transport infrastructure [J]. Social Sciences in China, 
2012(3):60-77

[2] ChenJinqing, Qu Tingting. Effect of inbound-outbound traffic facilities on the spatial power on urban development: A case study on Shanghai by bibliometric method [J]. Urban Development Studies,2016, (5):76-83.

[3] Hu Yan, Zhu Wenxia. Spatial spillover effects of transportation infrastructure: A regional comparison based on the eastern, central and western regions [J]. Inquiry into Economic Issues,2015,(1):82-88.

[4] Liu Shenglong, Zheng Shilin. Research on the cross-regional economic growth spillover effects of infrastructures_- The empirical results come from China's provincial panel data [J]. Industrial Economics Research,2013,(4):59-69.

[5] Roberto,Duran-Fernandez, Georgina Santos. Road infrastructure spillovers on the manufacturing sector in Mexico[J]. Research in Transportation Economics,2014,46(1):17-29.

[6] Alvarez-Ayuso, I.C., Delgado-Rodriguez. M.J., High-capacity Road Networks and Spatial Spillovers in Spanish Regions.[J] Transport Economic Policy,2012,46(2):281-292. 